\begin{tabular}{|l|l|}
\hline Coutinho y la vía prusiana a la modernización & Titulo \\
\hline Infranca, Antonino - Autor/a; & Autor(es) \\
\hline $\begin{array}{l}\text { De Raíz Diversa. Revista Especializada en Estudios Latinoamericanos (Vol. 2 no. 4 } \\
\text { jul-dic 2015) }\end{array}$ & En: \\
\hline México D.F. & Lugar \\
\hline $\begin{array}{l}\text { Programa de Posgrado en Estudios Latinoamericanos, Universidad Nacional } \\
\text { Autónoma de México }\end{array}$ & Editorial/Editor \\
\hline 2015 & Fecha \\
\hline $\begin{array}{l}\text { Coutinho, Carlos Nelson; Gramsci, Antonio; Modernización; Música; Cultura nacional; } \\
\text { Lukacs, Giorgy; Democratización; Dictadura; América Latina; Brasil; }\end{array}$ & Temas \\
\hline $\begin{array}{l}\text { Artículo } \\
\text { "http:/biblioteca.clacsoeduar/Mexico/ppel-unam/20160627031635/Antonino_Infranca__Coutinno___la_via_prusiana_a_la_modernizacion } \\
\text {.pdr" }\end{array}$ & URL \\
\hline $\begin{array}{l}\text { Reconocimiento-No Comercial-Sin Derivadas CC BY-NC-ND } \\
\text { http://creativecommons.org/licenses/by-nc-nd/2.0/deed.es }\end{array}$ & Licencia \\
\hline
\end{tabular}

Segui buscando en la Red de Bibliotecas Virtuales de CLACSO http://biblioteca.clacso.edu.ar

Consejo Latinoamericano de Ciencias Sociales (CLACSO)

Conselho Latino-americano de Ciências Sociais (CLACSO)

Latin American Council of Social Sciences (CLACSO)

www.clacso.edu.ar

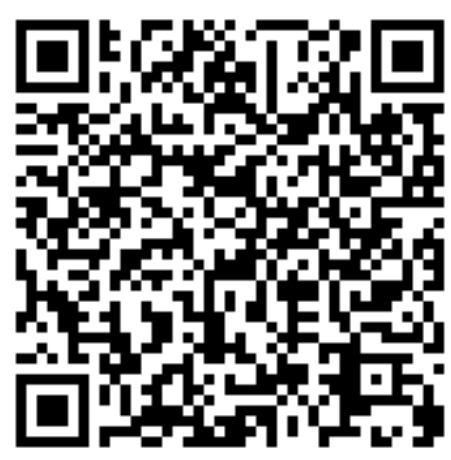




\title{
Coutinho y la vía prusiana a la modernización*
}

\author{
ANTONINO INFRANCA**
}

RESUMEN. El trabajo ofrece una propuesta de lectura sobre la obra del marxista brasileño Carlos Nelson Coutinho, en él se explora cómo en su temprana producción teórica adopta las ideas de Georg Lukács sobre la vía prusiana a la modernización pero, con el paso del tiempo, después de su exilio forzado por la dictadura brasileña, al plantearse la pregunta por la democratización su interés de reflexión sufrirá un viraje hacia las formulaciones teóricas de Gramsci. Una de las sugerencias de este trabajo es detectar la relación que se presenta entre la cultura nacional, la música y las propuestas de modernización.

Palabras Clave: Vía prusiana, revolución desde arriba, modernización, música, oriente.

Abstract: The author in this article deals with the interpretation of the work of the Brazilian Marxist Carlos Nelson Coutinho. It is explored how in his early theoretical production Coutinho adopted the ideas of Georg Lukacs on the Prussian way to modernization. However, a turn toward the theoretical formulations of Gramsci can be detected in the work of Coutinho when he considered the question of democratization after his exile forced by the Brazilian dictatorship. One of the suggestions of this article is to identify the relationship between the national culture, music and modernization proposals.

KEYWORDS: Prussian way, revolution from above, modernization, music, the East.

Recibido: 11 de febrero de 2015. Aceptado 18 de mayo de 2015.

\section{$\mathrm{E}$}

n Brasil, como en otras partes del mundo, en los años sesentas el marxismo tuvo una enorme influencia sobre los jóvenes intelectuales. Para aquella generación situarse en el marxismo era considerado un hecho natural; sin embargo, hoy en día la permanencia al interior de él de muchos de esos intelectuales es un hecho extraordinario, un verdadero y raro ejemplo de coherencia y fidelidad a la más antigua misión del intelectual. Aquellos jóvenes

Este es el texto de la conferencia del mismo título con motivo del 90 aniversario de la fundación del movimiento obrero brasileño. Al momento de la lectura Carlos Nelson Coutinho aún estaba vivo, lamentablemente en ocasión de entregar la redacción definitiva el gran amigo Carlos Nelson se había ido no hacía más de un mes. Dedico a su memoria este ensayo.

** Ministero Pubblica Istruzione y Stato Italiano <toni.infranca@gmail.com> 
continuaron la misión de intelectuales comprometidos, a la manera de Voltaire y de Fichte. Era un caso raro en el panorama latinoamericano donde habían aparecido ya antes casos aislados de intelectuales comprometidos como Mariátegui, pero aquí estamos frente a tres grupos de intelectuales. Menciono algunos nombres: Coutinho y Konder en Río de Janeiro, Henriques en Juiz de Forza, Cardoso ${ }^{1}$ y Löwy en São Paulo.

Los filósofos marxistas que tuvieron mayor difusión fueron Lukács y Gramsci. La difusión del pensamiento de Lukács encontró un obstáculo, relativamente superable, por el idioma en el cual el filósofo húngaro escribía, pues el alemán era escasamente conocido en Brasil; lo anterior con la excepción de Michael Löwy, quien fue uno de los primeros intelectuales brasileños que en 1969 escribió un ensayo donde analizó conjuntamente a Gramsci y a Lukács, específicamente sobre la teoría del partido. Los idiomas que permitieron la difusión del pensamiento de Lukács en Brasil fueron el francés, en un primer momento, y después el italiano. Se puede entender que el acercamiento al pensamiento de Gramsci no tuviera particulares obstáculos, justamente porque Gramsci escribía en italiano. Pero el primer acercamiento al pensador italiano hecho en español fue gracias a las traducciones del argentino José Aricó, cuya obra de difusión del pensamiento gramsciano en América Latina no alcanzará nunca suficiente reconocimiento.

A la mitad de los años sesenta, cuando inicia la difusión de las obras de Gramsci y de Lukács en Brasil, la represión de los militares impidió la formación de una cultura "marxista leninista" en la izquierda brasileña y por ello aquellos filósofos fueron relativamente poco leídos y estudiados. La izquierda brasileña consideró un Brasil atrasado y semicolonial, lo que ocasionó que fuera proclive a tendencias maoístas, guevaristas o bolcheviques, ${ }^{2} \mathrm{y}$ de hecho el exceso de bolchevismo acabó tomando como víctimas a aquellos jóvenes en la aplicación de las categorías lukácsianas y gramscianas para analizar la realidad brasileña. La mayor influencia filosófica en la izquierda brasileña fue la de Althusser, que ofrecía una concepción del marxismo similar a la de la ortodoxia soviética, todavía viva al interior del Partido Comunista Brasileño y, por lo tanto, más familiar a los que aun queriendo más autonomía respecto al condicionamiento

1 El futuro presidente de la República de Brasil cambió su perspectiva de interpretación con el paso del tiempo, para apoyar una interpretación liberal de Gramsci.

2 Cfr. Carlos Nelson Coutinho. "As categorias de Gramsci e a realidade brasileira" en Gramsci e a America latina, editado por C. N. Coutinho y M. A. Nogueira, São Paulo, Paz e Terra, 1993, pp. 103-4. 
ideológico del Partido, no pretendían modificar a fondo las concepciones que habían aprendido en una primera militancia ideológica marxista. Lentamente, también creció la influencia de Marcuse, sobre todo en los años cercanos a 1968, confirmando que, en el fondo, la cultura marxista brasileña vivía de los reflejos provenientes de Europa. Lukács y Gramsci eran considerados conservadores o pensadores ya superados frente a las nuevas tendencias frankfurtianas y althusserianas. La influencia de Althusser empujó también hacia formas de economicismo exasperado: cada aspecto de la vida social se resolvía en la relación capital/trabajo. Pero lentamente, la cuestión de la estructura cultural de Brasil tomó espacio en el debate intelectual y se constituyeron las condiciones para un regreso de Lukács y Gramsci a la atención de los intelectuales brasileños. ${ }^{3}$

Entre esos jóvenes, dos de ellos en particular, asumirán un papel relevante, Coutinho y Konder, mientras que Löwy se desplazará a Francia. Coutinho y Konder elaboraron verdaderas categorías teóricas para interpretar la realidad brasileña a partir de la reflexión lukácsiana y gramsciana, poniendo atención en la siguiente diferencia: Lukács será considerado como un filósofo y Gramsci como un teórico de la política. ${ }^{4}$ Una de las categorías lukácsianas utilizada para la interpretación de la historia brasileña, fue la de "vía prusiana a la modernidad".

Lukács analizó, en particular, en las obras Schicksalswende ("El Giro del Destino") y La Destrucción de la Razón la historia alemana para reconstruir todas las etapas del desarrollo cultural que condujeron a la tragedia del nazismo. Sobre todo en su ensayo "Über Preussentum” Lukács elabora su concepción de la "vía prusiana a la modernidad", pero no analiza la estructura económica de la Alemania en los márgenes o en el principio del desarrollo capitalista, que la llevó a ser la más grande economía capitalista de la Europa continental aunque no haya tenido colonias extraeuropeas, como las tuvieron Francia e Inglaterra. El análisis de Lukács carece de una profundización en el aspecto de las clases sociales y las relaciones de clase en la Alemania precapitalista; sin embargo, indaga más, aunque de manera parcial, en el análisis del desarrollo cultural y espiritual de la cultura alemana. Digo parcial por la ausencia de un análisis sobre el papel

\footnotetext{
3 Cfr. Ivete Simionatto, Gramsci. Seu teoria, incidencia no Brasil, influencia no Serviço Social, São Paulo, 2004, p. 109.

4 "Presença de Lukács no Brasil. Entrevista com Leandro Konder e Carlos Nelson Coutinho", en Lukács e a atualidade do marxismo, editado por S. Lessa y M. O. Pinassi, São Paulo, Boitempo, 2002, p. 163.
} 
de la música en el desarrollo de la cultura alemana y en cuanto al significado de la música alemana esa es una falta muy grave. Si se confrontan las obras del joven Lukács, dedicadas al análisis de la cultura italiana se nota cómo emerge en primer plano la continua referencia a la pintura en la escultura de Miguel Ángel, mientras en su análisis del romanticismo alemán se limita al análisis de la producción literaria, olvidando a Beethoven, Schubert, Brahms y pocas menciones a Wagner. Sin duda ese descuido se debe a su escaso conocimiento de la música, ${ }^{5}$ pero tiene un peso negativo en la construcción del desarrollo cultural alemán de mitad del setecientos hasta el nazismo. Sin embargo, es indudable la agudeza en su análisis de la literatura alemana en la época de afirmación del capitalismo en Alemania.

También Gramsci habló a su manera de una "vía prusiana a la modernidad". No usó esos términos pero sostuvo que Bismarck, un verdadero y particular modelo de prusianismo, pudo desplegar un cierto "cesarismo progresivo" que llevó a una "revolución desde arriba" en una Alemania que pasaba del modo de producción feudal al modo de producción capitalista. El papel de Bismark fue determinante sobre todo en la construcción de una estructura estatal que fuera capaz de influenciar e introducirse en la esfera económica para aumentar la producción de mercancías. Gramsci, que tenía frente a sí la trágica distorsión del modelo bismarckiano que había sido implementado en Italia a partir de 1876, podía juzgar las consecuencias de una adopción equivocada del modelo prusiano de desarrollo capitalista. A Gramsci no le pasa desapercibido que Italia tuvo un desarrollo capitalista típico de un país subdesarrollado; a pesar de haber tenido una gran tradición cultural. Los intelectuales no han participado en Italia en el desarrollo cultural de los italianos, salvo una importante excepción: Giuseppe Verdi. Los escritores italianos que buscaban ofrecer un idioma común a todos los italianos, que querían desarraigar los otros idiomas que se hablaban en la península (al verse degradados al nivel de "dialectos"), desarrollaban una obra difícil y sustancialmente imposible, considerando lo restringido de la base social que podía beneficiarse del texto escrito. Una situación totalmente inversa se encuentra en la recepción de la música, donde grandes masas de italianos escuchaban e incluso cantaban las obras líricas, in primis de Verdi, muy comprometido en la obra de unifi-

5 Esta falta de conocimiento el mismo Lukács no la oculta. En Pensamiento vivo reconoce que las partes dedicadas a la música de su gran Estética son, en realidad, las sugerencias de Dénes Zoltai, su alumno y experto en estética musical (Cfr. G. Lukács, Pensiero vissuto, tr. it. A. Scarponi, Roma, Editori Riuniti, p. 188). 
cación de Italia, pero también las obras de Rossini y Donizetti. Gramsci intuye ese fenómeno, aunque no le dedica demasiado espacio y Lukács no intuye para nada el rol hegemónico de la música alemana, salvo alguna superficial atención a Wagner -como ya mencioné- y desconoce totalmente el papel hegemónico de la música alemana en la cultura europea. No se puede pasar por alto el hecho de que la música en Europa o en el mundo por más de un siglo fue alemana, ya sea por autores, modelos y obras, con una sola excepción: Giuseppe Verdi.

No debe pasar inadvertido el papel de la música en la hegemonía de la cultura alemana sobre la cultura popular europea. Por cultura popular entiendo literalmente la cultura de masas de los ciudadanos europeos. Si los ciudadanos europeos con mucha rareza, solo de vez en cuando, podían acceder a los textos literarios alemanes, por otro lado, formaban su gusto estético por la música que llegaba de tierras teutonas. Músicos como Bach, Mozart, Beethoven, pertenecen a la formación cultural de centenares de millones de seres humanos dentro y fuera de Europa, tanto en el pasado, el presente y probablemente el futuro. Verdi fue el único músico que se contrapuso a esta hegemonía desbordante y, aun cuando ligó su música al canto en italiano, logró a la par de los músicos alemanes participar en la formación del gusto estético en centenares de millones de europeos. ${ }^{6}$ Donde no llegaron Leonardo y Manzoni, llegó Verdi. Más que Shakespeare, que narraba historias de reyes y nobles, Verdi ponía en escena, además de reyes y nobles, a los marginados de la sociedad de su tiempo: se piensa que La Traviata, en el fondo es una historia de amor entre una prostituta y un alto burgués, describe a una mujer, una marginada. También ésta es cultura popular. ${ }^{7}$

6 Gramsci en un artículo periodístico plasmó esta frase de Verdi y sus comentarios: "'Si, llegará un día en que usted no hable ni de la melodía, ni de la armonía, ni de las escuelas alemana, italiana, ni del pasado, ni del futuro, etc., etc., entonces tal vez comience el reino del arte': escribió Giuseppe Verdi, que no era alemán y trabajó para un arte lo suficientemente italiano $y$, sin embargo, le confiere más crédito que cualquier representante de la germanófoba demagogia" (A. Gramsci, "La rinascita gesuitica”, en “¡Avanti!" del 15 enero 1917, publicado en A. G., Cronache torinesi, editado por S. Caprioglio, Torino, Einaudi, 1980, pp. 706-7). Gramsci vio en Verdi el intelectual que se dirigía a la humanidad sin distinción de raza, idioma, cultura y, por tanto, que ayudó a construir la humanidad, como género que pertenece a todos los hombres, como hacen los intelectuales que participan en la lucha por la emancipación de las personas.

7 Gramsci solía asistir al teatro lirico y no dejó un texto dedicado a la ópera. Pero en un artículo de 1916 muestra su emoción frente a la ejecución del Himno de las naciones, con música de Giuseppe Verdi. Gramsci recuerda a Verdi como "el hombre que era el símbolo del país en los años del sagrado Risorgimento nacional”, el que con el mismo nombre 
Las clases sociales no faltan en el análisis gramsciano de la sociedad italiana de su tiempo y de la unificación en una nación. Gramsci, a diferencia de Lukács, es un intelectual que viene del pueblo, que conoce desde el interior la cultura popular, de la cual es representante y está muy ligado a su cultura originaria, es decir, la cultura sarda, habla otro idioma materno, el sardo, se da cuenta que el socialismo puede ser un elemento de cohesión social y de nacionalización de las masas, ${ }^{8}$ antes aún que el fascismo cumpla esa obra de nacionalización a su manera, con violencia y con superficialidad criminales.

Aquel grupo de jóvenes marxistas brasileños no tomó en cuenta ese límite en el análisis lukacsiano de la cultura alemana y no obstante que Lukács nunca pretendió que la "vía prusiana" fuera un modelo que había que extender a otras realidades sociales y geográficas, adoptaron aquella categoría. Cayeron probablemente en un error gramsciano, el cual como he dicho, adoptó el modelo bismarckiano. Bismark tenía su fascinación, debido al indudable éxito no solo en la formación de Alemania sino también en enfrentar la cuestión social, en una época en que los trabajadores, por lo menos en Italia, eran reprimidos salvajemente. Algunos primeros ministros italianos Depretis y Crispi, exponentes en primer plano de la clase dominante italiana, adoptaron explícitamente el modelo bismarckiano. La "vía prusiana" era en realidad, una concepción de Lenin utilizada como modelo a seguir para la modernización de la Rusia de su tiempo, y Lukács había adoptado esa concepción leninista ${ }^{9}$ para analizar la cultura alemana, es decir, la idea misma es de origen leninista. El mismo Gramsci,

fue capaz de interpretar "la aspiración irresistible de nuestro pueblo por la libertad". "En virtud de Giuseppe Verdi, todo el mundo sentía que sobre la batalla, hay espacio para un amor que no se detiene delante de ¡nuestro próximo enemigo!", el amor por la paz y por la humanidad (A. Gramsci, "L'inno delle nazioni" en "Avanti!" del 20 junio de 1916, publicado en A. G., Cronache torinesi, cit., p. 390-1).

8 "El socialismo se ha convertido en el único ideal unitario del pueblo italiano. El socialismo se ha convertido en la conciencia de unidad del pueblo italiano. Millones de italianos se han convertido en hombres, ciudadanos, porque ha habido una idea, el socialismo, que les ha sacudido, que les hizo pensar, que les ha plantado en cara su humillación y su vileza. El Partido Socialista es la imagen sensorial de esta unidad, esta conciencia, este nuevo mundo. (A. Gramsci, "Il socialismo e l'Italia", "Il Grido del popolo", n 687 del 22 septiembre 1917, en A. G., La città futura, a cura di S. Caprioglio, Torino, Einaudi, 1982, p. 351).

9 "No en vano Lenin indica esto como un caso típico de importancia internacional, como una manera desfavorable a la aparición de la moderna sociedad burguesa, y que él llama la vía prusiana. Esta observación de Lenin no debe ser limitada a la cuestión agraria, en el sentido estricto, sino que debe ser aplicado a todo el desarrollo del capitalismo y la 
por otro lado, recuerda en su conocido artículo "La Revolución contra el capital”, que Lenin la había rechazado una vez tomado el poder, como todo modelo ajeno a la historia de Rusia para desencadenar el proceso revolucionario emancipatorio, la "vía prusiana" había sido elaborada por Lenin muchos años antes de la revolución bolchevique, cuando la aristocracia y la alta burguesía rusas miraban justamente a Alemania como el país hegemónico de la cultura europea. Me limito a recordar cuál fue el papel de la música en el crecimiento cultural de Rusia a inicios del novecientos, y cómo Gramsci había cruzado en su vida privada aquella cultura musical rusa, habiéndose casado justamente con una violinista, Giuliana Schucht de origen alemán.

Por el contrario, Coutinho adoptó el modelo de la "vía prusiana" para entender la historia de Brasil y para una hipotética forma de desarrollo progresista del gran "gigante supino". Hay que tomar en cuenta también el hecho histórico de por qué se adopta ese paradigma de la "vía prusiana": la dictadura militar brasileña había cortado los puentes con el debate cultural europeo y como sucede en esos casos, los intelectuales se dedican al estudio de cuestiones no estrictamente políticas. Considero que Coutinho y Konder retoman esa categoría de Lukács para ofrecer a los intelectuales marxistas una alternativa a las categorías de interpretación de la cultura brasileña que habían desarrollado Sergio Buarque de Hollanda, Florestan Fernandes o Caio Prado Junior, que aun siendo cercanos a la izquierda no habían retomado desde el marxismo originarias categorías interpretativas del desarrollo histórico brasileño, sino que habían elaborado categorías interpretativas a partir de la realidad brasileña. De todas formas Florestan nunca empleó, como tampoco Caio Prado, la noción de "vía prusiana" y lo mismo vale para la noción de "revolución pasiva" de Gramsci. ${ }^{10}$

Lukács en la Moscú y la Budapest estalinianas había regresado a la crítica literaria y a la fundación de una estética marxista, ya eso le había causado dramáticos problemas de persecución estalinista por parte del aparato policiaco del partido. Es justamente con este Lukács que Coutinho y Konder interactúan en forma epistolar, además de teórica. Durante la

superestructura política que se tenía en la moderna sociedad burguesa de Alemania”. (G. Lukács, La distruzione della ragione, tr. it. E. Arnauld, Torino, Einaudi, 1959, p. 50).

10 C. Coutinho, "Marxismo e imagen do Brasil em Florestan Fernandes", en C.C., Cultura e sociedade no Brasil, cit., p. 250. Aunque Coutinho reconoce que el análisis de Caio Prado es paralelo al de Gramsci de "revolución desde arriba", $c f r$. C. Coutinho, "A imagen d Brasil em Ciao Prado Junior”, en Ídem., p. 231. 
dictadura militar, Konder y Coutinho se dedicaron a estudios de estética, ${ }^{11}$ siempre refiriéndose a Lukács y Gramsci, continuando de esa forma una lucha política camuflada. En efecto la dictadura militar fomentaba la adopción del estructuralismo francés en función antimarxista, así que seguir escribiendo de estética o de crítica literaria, citando dos pensadores marxistas, se volvía una verdadera obra de resistencia política ${ }^{12}$ aunque después serán obligados a vivir en el extranjero.

Coutinho advierte las dificultades de asumir un modelo ajeno, es decir, "prusiano" para analizar el desarrollo del capitalismo en Brasil, pero justifica esa adopción como si no pudiese haber otra forma de entender la historia de Brasil:

Las transformaciones que ha tenido nuestra historia no se han derivado de auténticas revoluciones, de movimientos surgidos de abajo hacia arriba que movilizaran el conjunto de la población, sino que se han verificado, se han realizado siempre por medio de una conciliación de los representantes de los grupos opositores económicamente dominantes, conciliación que se exime bajo la figura de reformas "desde arriba". Es evidente que el fenómeno de la "vía prusiana", así como Lenin lo fórmula, tiene su expresión general en la cuestión del pasaje hacia el capitalismo, la forma de adecuar la estructura agraria a las necesidades del capital. Sin embargo, generalizando el concepto se puede decir que sobre la base global de una solución "prusiana" para la cuestión de la transición al capitalismo, todas las grandes alternativas concretas vividas en nuestro país, directamente o indirectamente ligadas a aquella transición [...] han encontrado una respuesta 'prusiana': una respuesta en la cual la conciliación desde arriba nunca escondió la intención explícita de mantener marginalizadas o reprimidas [a...] las clases y estratos sociales subalternos. Por lo tanto, la transición de Brasil hacia el capitalismo [...] no ocurre solo en el marco de la reproducción ampliada de la dependencia, o sea, con el pasaje de la subsunción formal a la subsunción real frente al capital mundial; en estrecha relación con eso (ya que una solución no prusiana de la cuestión agraria aseguraría la condición para el desarrollo de un capitalismo nacio-

\footnotetext{
11 Por otra parte, la primera mención de Lukács por un intelectual brasileño había ocurrido de hecho durante el Congreso de la crítica literaria, en Assis, en julio de 1961. Antonio Candido argumentó que una lectura política de una obra literaria era posible, pero a condición de que la crítica del partido fuese matizada y potente como la de Lukács o abierta como la de Gramsci (Cfr. Lincoln Secco, Gramsci e o Brasil. Recepção e difusão de suas ideais, São Paulo, Cortez, 2002, p. 25).

12 "Presença de Lukács no Brasil. Entrevista com Leandro Konder e Carlos Nelson Coutinho", en Lukács e a atualidade do marxismo, cit., p. 173.
} 
nal no dependiente), esa transición se realizó también según el modelo de la 'modernización conservadora' de tipo prusiano. ${ }^{13}$

Y este modelo de "revolución desde arriba" continuo también con la dictadura de Getulio Vargas y con la dictadura militar a partir de 1964. Coutinho parece admitir que se trata de un tipo de modelo estructural, cita como fuente de autoridad de su tesis, la importante opinión de Florestan Fernandes que sostiene la existencia en Brasil de una "contrarevolución prolongada" o de una "dictadura hegemónica", revelando el mismo Fernandes una evidente influencia de las categorías gramscianas.

Coutinho entre líneas deja intuir la fascinación que siente hacia ese modelo de "vía prusiana", que es la misma fascinación que sintió Lukács hacia la concepción leninista de "vía prusiana" y en eso consistió el exceso del bolchevismo al que me referí antes. Como se puede deducir de la cita, a la "vía prusiana" leninista o lukacsiana Coutinho asimila también la concepción gramsciana de "revolución desde arriba" o "revolución pasiva”. Tal asimilación es explícita: "Es interesante observar todavía que el concepto lukacsiano de "vía prusiana" es esencialmente equivalente al concepto gramsciano de "revolución pasiva" (o "revolución restauración" o "revolución desde arriba"), con el cual Gramsci pretende sintetizar la ausencia de participación popular en el tipo de modernización conservadora, que ha sido propio del camino italiano al capitalismo". ${ }^{14}$

A la lukacsiana "vía prusiana" a la modernización, Coutinho y con él un grupo de jóvenes intelectuales marxistas, agregó la categoría gramsciana de revolución desde arriba de "carácter oriental" de la sociedad civil brasileña, aunque después Coutinho sustentará que no todas las sociedades latinoamericanas serán "orientales", refiriéndose probablemente a la Argentina y a Chile. ${ }^{15}$ Gramsci entendía por oriental una sociedad civil pasiva con un estado particularmente ampliado, casi a punto de sofocar a la sociedad civil, y Brasil en el curso de su proceso de modernización, presenta muchos aspectos de pasividad y de exceso de presencia del

13 Carlos Nelson Coutinho, "Cultura e società in Brasile", tr. it. A. Infranca, in Rivista di studi portoghesi e brasiliani, a. III, 2001, Pisa, p. 183; cfr. Además Carlos Nelson Coutinho. "As categorias de Gramsci e a realidade brasileira", cit., pp. 110-112.

14 Ibíd., p. 184, nota 15. En "Gramsci e nós", Coutinho vuelve sobre la relación entre "vía prusiana" y "revolución desde arriba", cfr. C.N. Coutinho, "Gramsci e noi", en Gramsci in America latina, editado por D. Kanoussi, G. Schirru, G. Vacca, Bologna, Il Mulino, 2011, p. 171.

15 C. N. Coutinho, Il pensiero politico di Gramsci, tr. it. A. Pelliccia, Milano, Unicopli, 2006, p. 115. 
estado. ${ }^{16}$ Como recuerda el mismo Coutinho y eso puede hacer relación con la dependencia colonial respecto a un país atrasado y pasivo como Portugal. En general Coutinho indica que los Estados latinoamericanos tienen un carácter marcadamente oriental. ${ }^{17}$

Según el juicio de otro gramsciano, el argentino José Carlos Portantiero, la América Latina no es "Oriente", eso está claro, pero se acerca mucho al Occidente periférico y tardío. En América Latina, en forma todavía más evidente que en las sociedades del segundo "Occidente" que se constituyeron en Europa a finales de siglo xix, son el estado y la política quienes configuran la sociedad. Pero se trata de un estado que, aunque trata de constituirse en una comunidad nacional, no alcanza los grados de autonomía y soberanía que caracteriza a los modelos "bismarckiano" y "bonapartistas" ${ }^{18}$ Portantiero rechaza la posibilidad de una "vía prusiana" a la modernización, pero el pensador argentino no es lukacsiano es gramsciano, y más que rechazar la adopción de la "vía prusiana", revela que las categorías gramscianas cuando son utilizadas en contenidos históricos determinados, "bismarckismo" o "bonapartismo", no resultan pertinentes, específicamente en la interpretación de la realidad latinoamericana. En realidad las categorías gramscianas como "revolución desde arriba" o "revolución pasiva" son casi siempre más formales, más vacías de contenido histórico que aquella lukacsiana de "vía prusiana", porque no tiene la función de modelo, sino que indica acciones dinámicas, de instrumentos de comprensión de las dinámicas de la realidad histórica y social. Por ese carácter formal las categorías gramscianas son más idóneas para la elaboración teórica y para ser adoptadas en la comprensión de una realidad histórica-social ajena a la italiana para la que Gramsci las usó, Portantiero habla de un pensamiento "abierto". "El pensamiento de Gramsci, abierto a cada historia nacional, teórica y práctica política que trate de experimentarse en "idiomas particulares", para experimentar su propia

16 Carlos Nelson Coutinho. "As categorias de Gramsci e a realidade brasileira, cit., p. 116-121. Coutinho admite que el carácter oriental de Brasil es válido hasta el tiempo del imperio, mientras que la occidentalización de arriba comienza en los años veinte y se expande con la dictadura de Vargas. Pero si Brasil era una sociedad de tipo oriental, entonces la reflexión de Gramsci podría tener valor sólo historiográfico, dice Coutinho.

17 C. N. Coutinho. "As categorias de Gramsci e a realidade brasileira" in Gramsci e a America latina, editado por C. N. Coutinho e M. A. Nogueira, São Paulo, Paz e Terra, 1993, pp. 119.

18 Juan Carlos Portantiero, "Gli usi di Gramsci", Apúd., C.N. Coutinho, "Gramsci e noi" en Gramsci in America latina, editado por D. Kanoussi, G. Schirru, G. Vacca, Bologna, Il Mulino, 2011, p. 84. 
validez, aparece como un estímulo útil, un instrumento crítico permeable, lejano de esquemas rígidos". ${ }^{19}$ El otro mayor difusor de Gramsci en América Latina, José Aricó, afirma: "Gramsci fue un ingrediente irremplazable de diferentes combinaciones culturales y pudo serlo por el carácter de su obra: abierto, asistemático, capaz de admitir desviaciones. ${ }^{20}$ Apertura, adaptabilidad, no sistematicidad, son todos elementos que caracterizan el marxismo de Gramsci y lo distinguen también del marxismo de Lukács, qué, si bien abierto, es sistemático y poco adaptable a realidades diversas de la alemana, tampoco de la húngara se puede adaptar dramáticamente, eso se nota por su escaso arraigo.

No hay duda de que Coutinho tiene razón cuando habla de pasividad con relación a las transformaciones desde arriba, a la modernización que mantiene las relaciones de clases existentes en ventaja de las clases dominantes, además de la subordinación de la economía brasileña al capitalismo internacional. La "vía prusiana" tuvo también graves consecuencias sobre los intelectuales brasileños, "porque el instrumento y el espacio de la consideración de clases fue siempre el Estado, se ha verificado un reforzamiento de lo que Gramsci llamaba 'sociedad política' (los aparatos burocráticos y militares que ejercían el dominio por medio del gobierno) con menoscabo de la 'sociedad civil' (un complejo de aparatos ideológicos mediante los cuales una clase, o un grupo de clases, lucha por la hegemonía o por la capacidad de dirigir el conjunto de la sociedad)". ${ }^{21}$ De ahí una subordinación de los intelectuales al Estado y una falta de autonomía de los aparatos ideológicos de la sociedad civil respecto del dominio del gobierno. Así, el bloque social que sostuvo la dictadura militar, lentamente trató de cooptar a su servicio, subordinándolos, a los intelectuales, también a aquellos que aspiraban a representar los derechos de las clases explotadas. Coutinho se da una imagen eficaz, cuando sostiene que la cultura brasileña se vuelve "ornamental". ${ }^{22}$ Naturalmente terminada

19 Ibíd., p. 87. Posteriormente Coutinho cambió ligeramente la perspectiva desde la que considera América Latina, y Brasil en particular, con respecto a lo que había afirmado en un principio. Se acercó más a la perspectiva de Portantiero, con el argumento de que América Latina tenía afinidades con la Italia fascista, porque ambas realidades sociales y culturales eran periférica para el desarrollo de las grandes naciones capitalistas ( $c f r$. Carlos Nelson Coutinho, Il pensiero politico di Gramsci, cit., p. 165).

20 J. Aricó, "Il ruolo degli intellettuali nella diffusione di Gramsci in America latina", tr. A. Infranca, in Gramsci nel mondo, a cura di M. L. Righi, Roma, Istituto Gramsci, 1991, p. 177.

${ }^{21}$ C. N. Coutinho, "Cultura e società in Brasile", cit., p. 184.

22 Ídem., p. 185 
la dictadura militar, una parte de los aparatos ideológicos de la sociedad civil -por ejemplo, la televisión- ha fagocitado al resto de la sociedad civil. ${ }^{23}$

Coutinho extiende también a los intelectuales brasileños una actitud pasiva, acusándolos de refugiarse "en el intimismo de la sombra del poder”, que es una categoría que Lukács utilizó al confrontarse con los intelectuales burgueses. Y en ese caso, Coutinho atina porque "el intimismo a la sombra del poder" es una actitud típica de los intelectuales burgueses bajo cualquier meridiano y, por lo demás, típico es su "conformismo", es decir, el abandono de ideologías o concepciones del mundo en favor de otras ideologías más útiles según la transformación de las circunstancias sociales y políticas. Se tiene así una "apología indirecta de lo existente" y no ya una crítica abierta a lo existente. ${ }^{24}$ Es la confesión de la pérdida de sentido por parte de los intelectuales, de su falsa conciencia, la clausura en su propio particularismo sin más comprensión de lo universal. Coutinho caracteriza así esa actitud: "Podemos considerarlo esquemáticamente, como manifestación de la 'falsa conciencia' del intelectual intimista que desea más o menos identificarse con el pueblo, pero es incapaz de hacerlo 'desde adentro', asumiendo la 'conciencia posible' de las creencias populares como punto de vista estructurador de sus creaciones: su lazo con el pueblo es así, para usar una expresión de Gramsci, precedentemente citada, 'apenas retórico"' 25 . El fenómeno del transformismo fue denunciado también por el viejo Coutinho a propósito de los muchos intelectuales que abandonaron sus juveniles posiciones marxistas hacia las más cómodas y rentables concepciones neoliberales. Pese a que el transformismo ocurre siempre molecularmente, es decir en casos singulares, no es pensable un cambio de campo en masa, como ocurrió en la Iglesia alemana en los tiempos de Lutero.

Justamente el 'intimismo a la sombra del poder' indica que Coutinho se refiere a los escritores e intelectuales de punta de la cultura brasileña,

23 Aunque este fenómeno fue captado por Coutinho: "Tal vez no estaría mal, antes de ciertos fenómenos culturales contemporáneos, también hablan de la" enfermedad senil "de lo nacional-popular. Se produce cuando ciertos elementos de esta orientación realista e historicista, aunque despojada de su intención crítica y totalizante, se utilizan en los productos propios de un arte puramente "agradable", digerible o comercial, cuyo valor estético es prácticamente cero y cuya implicaciones ideológicas son a menudo negativas” (Ídem., p. 68).

24 Ídem., p. 55. Coutinho también cita aquí a Lukács, Distruzione della ragione, cit., p. 5 y 205-206.

25 Ídem., p. 67. "Conciencia posible" es otra expresión lukacsiana, tomada de Storia e coscienza di classe. 
no a la cultura popular. En esa elección está revelando su concepción de la cultura: la gran cultura es aquella que forma la consciencia de la nación. El gramsciano argentino Agosti, punto de referencia del gramscismo de Coutinho, es todavía más explícito: "la literatura de un pueblo siempre es reflejo de su vida más profunda". ${ }^{26} \mathrm{La}$ frase de Agosti es lukacsiana por dos motivos: el uso del término "reflejo" y la presunción de que la literatura sea el reflejo de la cultura popular. Pero esa afirmación es falsa, es usada en la cultura italiana por el simple hecho que los italianos que usan cotidianamente el idioma italiano son la mayoría de la nación, por lo menos desde hace cincuenta años. Esta afirmación es válida para la cultura alemana y la brasileña, porque en Brasil no existen idiomas distintos al portugués en su uso cotidiano. Pero ¿̇la literatura de la burguesía brasileña expresa la conciencia profunda del pueblo brasileño? Esa es una cuestión que enfrentaremos más adelante.

El modelo de la "vía prusiana" de modernización se podría incluso usar como un modelo estructural del desarrollo del capitalismo brasileño, porque la globalización hoy existente, no hubiera sido posible sin una subordinación pasiva de las economías productivas en relación con el capitalismo financiero. Parece propio del capitalismo ser un modo de producción de la riqueza, que necesita del desarrollo desigual de las partes que intercambian capital, materias primas y fuentes energéticas; de la pasividad de la fuerza de trabajo frente al capital, del desarrollo conservador del orden existente de la sociedad civil, y, además, la universalización de esas paradojales condiciones económicas al interior del conjunto complejo de la sociedad civil en todos sus aspectos. La lógica que rige en el mundo capitalista, en la práctica es la lógica dialéctica, que no admite la síntesis superadora de los contrarios y prefiere la permanencia de las situaciones opuestas y paradojales. Es justamente la paradoja de la figura lógica, típica del capitalismo.

Resulta paradójico utilizar un modelo elaborado por una sociedad no esclavista y monoracial, cuál era Prusia y Alemania, Rusia o Italia, para caracterizar una sociedad esclavista y multirracial como es Brasil. Ya Italia y Rusia no presentan uno de los elementos más característicos de la sociedad prusiana: los Junker, una aristocracia feudal que se pone al servicio del Estado y del soberano, sin interferir mínimamente con su acción

26 Hector Agosti, "Introduzione a Letteratura e vita nazionale", en Gramsci in America latina, cit., p. 71 . 
política. En Rusia la aristocracia fue tradicionalmente opuesta al estado central, en Italia la aristocracia era en realidad, una nobleza de toga que vivía "en el intimismo a la sombra del poder". Falta en la adopción de la "vía prusiana" una constatación simple de la diferencia entre esclavismo y feudalismo: en el primero el cuerpo del trabajador pertenece a los propietarios de los medios de producción, es en el fondo un simple instrumento de producción como un instrumento de trabajo, entonces no tiene que ser explotado demasiado a menos que no cueste poco y pueda ser recambiado fácilmente, condiciones que no estaban presentes en el Brasil esclavista; en el segundo, solo una parte del tiempo del trabajo pertenece al propietario de los medios de producción en cuanto se liberó de la servidumbre de la gleba, pagando el trabajo como si fuera una simple mercancía, un instrumento de trabajo, sin preocuparse del agotamiento del cuerpo del siervo que era el portador de la fuerza de trabajo.

El juicio que el primer grupo de intelectuales marxistas expresó sobre la cultura brasileña, sobre el conjunto del desarrollo de la modernidad en Brasil, revela distintos aspectos de la recepción de Gramsci y de Lukács en Brasil, pero también de las exigencias que surgieron de esa recepción. En primer lugar, la búsqueda en el desarrollo de Brasil de elementos analógicos a aquellos europeos, lo cual revela sustancialmente la tentativa de ligar a Brasil con el desarrollo de la modernidad que se realizó en otras partes del mundo, en el fondo esta fue una forma anticipada de globalización. En segundo lugar, el rechazo explícito del proceso de modernización que se había instaurado en Brasil y el intento de ofrecer una alternativa posible a aquel proceso. Son varias las tendencias reveladoras de la intencionalidad política, además de teórica, de aquel grupo de jóvenes. Hay también la juvenil tendencia de sobrestimar las teorías que aparecen más en sintonía con su propio modo de pensar, pero eso es un hecho natural que revela a su vez la fuerte tensión moral, el compromiso ético de esos jóvenes en relación con los destinos de su propio país.

Si se observa más en profundidad su superación teórica, y se analiza el carácter lógico de la operación, me parece evidente que esos jóvenes, justo por esa condición, habían tratado de aplicar al Brasil los esquemas teóricos que habían sido elaborados para otras realidades sociales. Si miramos la naturaleza lógica de su operación teórica, se nota que han aplicado a Brasil lo que Kant, en la Crítica del Juicio, definió como juicio determinante: el particular es asumido bajo la forma de lo universal. Kant afirma, 
con precisión detallada: "si esta dado lo universal (la regla, el principio, la ley), el juicio que opera en función de lo particular (aun si ese, en cuanto juicio trascendental, ofrece a priori las condiciones según la cuales solo puede ocurrir subsunción a aquel universal), es determinante". ${ }^{27} \mathrm{La}$ "vía prusiana” es asumida como una ley universal de desarrollo de sociedades atrasadas, todavía feudales, hacia la modernización capitalista; mientras la sociedad brasileña, es el particular en aquel universal que es asumido. Habría que repensar el hecho de que la "vía prusiana" fue adoptada por todas las sociedades atrasadas para iniciar su propio proceso de modernización capitalista. Por ejemplo, la "vía prusiana" fracasó en la entera Escandinavia, donde el modelo prusiano de modernización nunca fue adoptado, en ventaja, por el contrario, de una evolución pacífica y no dirigida desde arriba de la modernización capitalista.

El límite lógico de esa asunción es indicado por Kant en su carácter a priori, como se nota en la cita anterior, y deriva de la falta de autonomía: "el juicio determinante no tiene para sí mismo principios que funden conceptos de objetos. No es autónomo, porque subsume solamente a leyes dadas y a conceptos, tomados como principios. Por lo tanto, no está expuesto al peligro de una antinomia propia, una contradicción de sus principios" ${ }^{28}$ Por falta de autonomía se debe entender que el juicio determinante, es decir, la asunción del particular (Brasil) en el universal (la modernidad capitalista), no se expresa, por las leyes propias del objeto, en nuestro caso por un análisis de la sociedad brasileña, según la propia estructura ontológica. Esta asunción evita el problema de la contradicción de sus principios, como recuerda Kant, justamente porque no es admitida la estructura ontológica del objeto. Pero si se evita la contradicción entre la ley universal y el particular, se delimita a la "noche donde todas las vacas son negras", para decirlo con Hegel. Escapa justamente a la autonomía del objeto, la ley regulativa interna del objeto. La "vía prusiana", también según la concepción leninista, es un modelo de desarrollo moderno de las sociedades civiles europeas, pero como he dicho antes, ${ }_{¿}$ Brasil es una sociedad civil a la europea?

En el análisis de Coutinho, por ejemplo, aparecen marginalmente algunos de los elementos más típicos de la cultura popular brasileña. La negritud, o mejor dicho la extraordinaria influencia de la cultura africana

27 I. Kant, Critica del giudizio, tr. A. Gargiulo, Bari, Laterza, 1979, pp. 18-19.

28 Ibíd., p. 255. 
sobre la entera sociedad civil brasileña. Jorge Amado resumió esta situación con las siguientes palabras: "Brasil es un país mestizo. No somos ni negros ni blancos, somos mulatos de tonalidades diferentes, cada uno en la búsqueda de su propio color definido". ${ }^{29}$ Amado era comunista y marxista como Coutinho, todavía más, Amado era bahiano como Coutinho. Darcy Ribeiro pone en evidencia otro elemento de modernización en Brasil que no ha sido mencionado por Coutinho: "Con la expansión de la Revolución Industrial se agrava la obsolescencia de Portugal, que no logrando estructurarse como formación capitalista mercantil se vuelve arcaica y deviene igualmente incapaz de integrarse autónomamente a la nueva civilización”. ${ }^{30}$ En la práctica, la dependencia del Brasil colonial respecto a un país atrasado, marca fuertemente el desarrollo interior de Brasil independiente. Y esa situación no está presente en la "vía prusiana" de Alemania, país hegemónico culturalmente en Europa; gracias a su hegemonía artístico musical, ya antes de su primera modernización. Se nota un esfuerzo, comprensible por salir de ese atraso supuesto de la cultura brasileña, por parte de aquel grupo de jóvenes intelectuales marxistas.

En verdad, Brasil es el más logrado ejemplo de síntesis cultural, justo gracias al sincretismo de su cultura popular que ha potenciado el fantástico capital humano de Brasil que son justamente los brasileños, que posiblemente no tengan un nivel cultural equivalente al de los europeos, pero tienen una cultura popular mucho más arraigada que la europea. Esa cultura popular brasileña era fuerte también al inicio de los años sesenta, cuando aquellos jóvenes empezaron a mirar fuera de las fronteras de Brasil. En particular en la música, un verdadero y propio arte popular, que justamente en esos años explotaba en el fenómeno de la Bossa nova, la primera verdadera alternativa a la hegemonía artístico-musical de la cultura anglófona; alternativa porque se funda, por un lado, sobre el arraigo de sus propias tradiciones artísticas y, por el otro, al mismo tiempo, sobre la renovación de aquellas tradiciones por medio del encuentro con la música hegemónica dominante, el jazz estadounidense, todavía un caso de música que nacía de la parte de la población dominada, los negros afroamericanos, pero que también había conquistado el escenario mundial. Era una lucha contrahegemónica por parte de los antiguos esclavos del Brasil, que

\footnotetext{
29 J. Amado, Bahia de todos os Santos. Guias de ruas e misterios, Rio de Janeiro, Record, 1996, p. 408. La traducción es mía, pero también hay una edición italiana: Milano, Garzanti, 1992.

30 D. Ribeiro, Teoria do Brasil: los brasileros, Petropolis, Vozes, 1990, p. 48.
} 
expresaban una cultura alternativa a la de los restringidos grupos de intelectuales refugiados en el "intimismo a la sombra del poder", casi todos escritores, y alternativa también a la gran hegemonía cultural global estadounidense, dominante en el campo de la música y del cine. Se trata de una cultura nacional popular, que puede ser analizada con las categorías que el mismo Coutinho indica: "en ese sentido, lo nacional popular aparece objetivamente como oposición democrática en el plano de la cultura, a las varias configuraciones concretas asumidas por la ideología del 'prusianismo' en el curso de la evolución brasileña". ${ }^{31}$ En cuanto a la "oposición democrática", lo nacional popular no puede ser asimilado a las categorías de la alta cultura brasileña, pero no es por lo mismo subalterno a la alta cultura. Coutinho retoma de Lukács, todavía una vez más, la categoría del "realismo crítico" para interpretar lo nacional popular. ${ }^{32}$ No hay duda de que la cultura popular es realista por naturaleza, no logra esconder su real condición de explotación y de marginación y en la narración de su condición de existencia denuncia justamente la explotación y la marginación.

Pero muy simbólicamente, como en el análisis de Lukács de la cultura alemana, también en la deconstrucción de Coutinho de la cultura brasileña, falta un análisis de la cultura musical brasileña. ${ }^{33}$ Sin embargo, la música es una forma artística que logró difundir la cultura brasileña en todo el mundo, junto a valores fundamentales de la sociedad civil brasileña, como la alegría, el placer de vivir, la sexualidad, además de haber ocupado un papel importante en la misma cultura literaria brasileña con autores como Vinicius de Moraes que supo modernizar la cultura literaria brasileña con sus poesías/canciones.

También en Lukács está totalmente ausente un análisis de la antropología alemana, y a las sublimes páginas de reconstrucción de la afirmación del irracionalismo en Alemania, contenidas en La Destrucción de la Ra$z o ́ n$, no sigue una reconstrucción de la psicología social alemana después de la derrota de la Primera Guerra Mundial. Pero Lukács no era un historiador ni un sociólogo, entonces no estaba interesado en la reconstrucción del material humano en referencia de sus análisis, se limitaba a poner en evidencia las tendencias teóricas y filosóficas de una cultura. Además,

31 C. N. Coutinho, "Cultura e società in Brasile", cit., p. 188.

32 Cfr. Ídem, p. 190.

33 Sus estudiantes me dicen que él habló extensamente de la música brasileña en conferencias universitarias. Lamentablemente no tengo ningún material para reconstruir estas lecciones y valiosas observaciones de Coutinho sobre la música brasileña. 
Lukács era totalmente ajeno al análisis de la cultura popular; no lo fue con la cultura alemana, ni tampoco con la cultura húngara. Lukács era hijo de un director de banco, una de las personas más ricas de Hungría, su madre, si bien era húngara no hablaba húngaro. Su lengua materna era el alemán y usaba el húngaro solo con su padre y con la servidumbre de la casa. Era ajeno a la cultura del pueblo, en el cual vivía preso, y la cultura era para él un producto de intelectuales. Lo mismo se puede decir del análisis de Coutinho: él se concentra en la explicación de las tendencias teóricas y filosóficas del Brasil moderno, sin abundar en lo particular, sin tener en cuenta la antropología que aquellas tendencias expresan. Coutinho hace un listado de los intelectuales brasileños más relevantes del ochocientos, pero está ausente un mínimo señalamiento a la cultura popular brasileña.

En Gramsci, por otra parte, aparecen siempre puntualmente al lado del análisis de la historia de la sociedad civil italiana, observaciones sobre la psicología social de los italianos; no obstante, las enormes diferencias entre las varias psicologías regionales presentes en Italia. Gramsci es sustancialmente un hombre político que quiere cambiar esa antropología, entonces la tiene que conocer, analizar, definir para poderla transformar en su objeto de acción, además de tener una profunda atención y capacidad de comprensión de la cultura popular, porque él mismo era expresión de esa cultura popular. En efecto, Gramsci es uno de los pocos intelectuales marxistas que viene de la clase social de los campesinos, es prácticamente un hijo del pueblo que habla en sardo, un idioma del sur, excluido del desarrollo capitalista de la Italia moderna.

Coutinho, pero con él todo el grupo de los jóvenes intelectuales marxistas, quedo fascinado con la concepción lukacsiana de la "vía prusiana" y la adoptaron sin un análisis crítico, sin una evaluación de su aplicabilidad al Brasil, sin una revaloración de aquello más original y auténtico que Brasil podía ofrecer. Puede ser que no tuvieran en cuenta tampoco quién había expresado originalmente esa concepción. A su vez, Lenin no era un hijo del pueblo ruso, conocía poco las clases sociales rusas excluidas por el desarrollo moderno del capitalismo, también porque había vivido más de una década en el extranjero. Era un intelectual europeo, como Lukács, y conoció finalmente el proletariado ruso solo a su regreso a Rusia, en 1917.

No emergen en el análisis de Coutinho el carácter global, ante litteram, de la cultura brasileña, una cultura nacida por el encuentro entre la cultura africana, la cultura indígena y una cultura europea periférica, como la 
portuguesa, a la cual se agregaron después elementos de cultura italiana, de los migrantes a partir de la segunda mitad del ochocientos, justo en la ocasión del nacimiento del Brasil independiente. La religión, la cocina, el idioma, la espiritualidad brasileña, son resultado de esa obra de mestizaje, mencionada anteriormente, pero qué hace de Brasil y de los brasileños lo que Ribeiro definió como un "pueblo nuevo". Diría que la globalización actual ha sido anticipada justamente por Brasil, que siguió una propia vía autónoma de evolución análoga, pero no similar, a la de los Estados Unidos. Análoga significa paralela, pero no reproductiva, porque el mestizaje brasileño está ampliamente más integrado de lo que es la asunción de la cultura afroamericana del protestantismo Wasp (White Anglo-Saxon Protestant) en los Estados Unidos y la conservación de la cultura africana indígena es mayor que en la cultura norteamericana donde la cultura indígena despareció y la africana se vacío totalmente de sus contenidos religiosos. Éstas son señales de lo extraordinario de Brasil.

A finales de los años setenta, Coutinho regresa a Brasil, después de un período de exilio en Italia, Portugal y Francia a causa de la persecución de la dictadura militar por su compromiso político y cultural con el Partido Comunista del Brasil. ${ }^{34}$ Recién retornado a Brasil, Coutinho publicó su ensayo "La democracia como valor universal", que tuvo un efecto disruptor en los ambientes políticos de la izquierda. Para Coutinho la dictadura militar representaba el punto más alto de la "vía prusiana" a la modernización, ahora su superación debía pasar por la adopción del valor de la democracia en sí por parte de las fuerzas populares al interior de una estrategia hegemónica. Claramente Coutinho ponía a un lado la "vía prusiana" y acentuaba el carácter gramsciano de su interpretación de la modernización de Brasil. El cambio de perspectiva es explícitamente expuesto en el ensayo "Gramsci y nosotros", que hace parte del volumen homónimo que contiene el ensayo "La democracia como valor universal". ${ }^{5}$

\footnotetext{
${ }^{34}$ Los intelectuales del llamado Primer Mundo deberían pensar más en este aspecto del exilio, común a muchos intelectuales del mundo periférico, que se ven obligados a abandonar por un periodo, o para siempre, su propio país a causa de la libre expresión de sus ideas. Es un aspecto que es citado a menudo superficialmente sin tener en cuenta lo que significa la libertad de expresión y el desarraigo de su propia cultura y su propia lengua, así como el enraizamiento forzado en otra cultura y otro idioma, a menudo los de la antigua metrópolis colonial.

35 Cfr. C. N. Coutinho, "Gramsci e nós", también C. N. Coutinho, A democracia como valor universal, São Paulo, Ciencias Humanas, 1980, pp. 46-60.
} 
Su toma de posición a favor de la democracia, estuvo influenciada por el método y la praxis democrática del eurocomunismo de Berlinguer, lo cual creó polémicas, empujó a tomas de posturas y a tomas de distancia del método leninista y manualístico de algunos sectores de la izquierda brasileña. También fueron influenciados por ello los partidos no comunistas brasileños. ${ }^{36} \mathrm{El}$ mismo Coutinho había superado su juvenil exceso de bolchevismo y había abierto un nuevo debate en la izquierda brasileña sobre el valor ético de la democracia. Esta vez Coutinho había adoptado las categorías gramscianas, junto a las lukacsianas, pero del Lukács de $L a$ ontología del ser social, ${ }^{37}$ es decir, del Lukács atento estudioso de las tendencias de desarrollo de la sociedad civil. No es casual que justamente a ese Lukács dedique la mayor atención Coutinho y José Paulo Neto, porque es el Lukács que ofrece categorías más aptas para la interpretación de la sociedad civil, el gran campo de conflictos y contradicciones de clase, donde es posible entrever las tendencias de desarrollo modernizadoras. El único límite que Coutinho ve en este último Luckács es su retorno a Lenin, considerado "simplificador y utópico". ${ }^{38}$

A este análisis de la sociedad civil, conducido por las categorías de la Ontología lukacsiana como extrañación, ideología, trabajo, reproducción social, se agrega el concepto gramsciano de democracia, de guerra de posición por una siempre más avanzada emancipación y liberación de las clases trabajadoras. Coutinho escribió ensayos fundamentales para la reconstrucción de una ontología del ser social en Gramsci y para la búsqueda de una teoría política en la Ontología lukacsiana. ${ }^{39}$ En un pasaje de "Gramsci y nosotros", Coutinho sintetiza con claridad lo que entiende por presencia, en Gramsci, de una ontología materialista del ser social: "En la definición de la sociedad civil él [Gramsci], pone en práctica la auténtica ontología materialista del ser social, que es la base del método de Marx:

36 Cfr. Marco Aurelio Nogueira, “Gramsci, a questao da democracia e a esquerda no Brasil”, en Gramsci. A vitalidade de um pensamento, editado por A. Aggio, São Paulo, Unesp, 1998, p. 137.

37 Puedo quedarme con el recuerdo de una de las muchas y siempre agradables conversaciones que tuvo en la mayoría de lugares del planeta, como Buenos Aires, Río de Janeiro, São Paulo, Roma, Tivoli. En una de estas conversaciones me confesó (en Buenos Aires, me parece recordar) el interés y la emoción con que vio, una noche, en una vitrina de una librería, en Bolonia, el primer volumen de la traducción italiana de la Ontología del ser social, de Lukács. A la mañana siguiente se apresuró a comprar el libro, pero fue precedido por José Paulo Neto, sin embargo, en otra librería pronto encontró otra copia del libro.

38 C. N. Coutinho, Lukács Proust e Kafka, Rio de Janeiro, Civilização Brasileira, 2005, p. 31.

39 C. N. Coutinho, Il pensiero politico di Gramsci, cit., p. 88. 
No hay forma (o función) social sin una base material, no hay objetividad social que no sea la resultante de la dialéctica entre esa forma y su soporte material". ${ }^{40}$ Naturalmente, esa afirmación parte de una perspectiva lukacsiana, pero también de una indicación precisa de una búsqueda dirigida a complementar el pensamiento de Gramsci con el de Lukács y viceversa.

El segundo Coutinho, el que regresa del exilio europeo, es un intelectual maduro, más crítico hacia sus mismos pensadores de referencia, más libre de prejuicios esquemáticos e ideológicos; por ejemplo, no duda en reconocer, sea en Gramsci o en Lukács, un común carácter idealista y antipositivista. ${ }^{41}$ Sobre el antipositivismo la tesis de Coutinho era universalmente aceptada, pero el carácter idealista del marxismo de Lukács y Gramsci era usado como una acusación y no un valor positivo de su marxismo. Coutinho quiere volver a revisitar las raíces del marxismo y revalorar la razón burguesa como el mismo Marx sostenía, y además abrirse a otras tendencias culturales que iban afirmándose en Brasil, como la pedagogía de Paulo Freire, un importante aliado en la lucha por la emancipación de las enormes masas de pobres y de fabelados. Los esquemas ideológicos tradicionales del marxismo estalinista, como nueva ideología sin ninguna tradición, son puestos en discusión y además se buscan las raíces históricas del marxismo. Esto es posible a condición de que haya una constancia, una permanencia en los valores éticos y políticos del marxismo y esa constancia es indicada por Coutinho justamente en la concepción de la democracia.

Justamente sobre la democracia se notan las aperturas más significativas de la propuesta de Coutinho, que él enlista: "La pluralidad de sujetos políticos, la autonomía de movimientos masas (de la sociedad civil) en relación al Estado, la libertad de organizaciones, la legitimización de la hegemonía a través de la obtención de un consentimiento mayoritario, todas esas conquistas democráticas continúan teniendo un pleno valor en una sociedad socialista". ${ }^{42}$ El marxismo brasileño en general, y el Partido Comunista Brasileño en particular, el "moderno príncipe" para Coutinho, estaban ligados a importantes y molestas reservas ideológicas en relación a la democracia o hacia el Estado de derecho, que se confundían como

40 C. N. Coutinho, "Gramsci e noi", cit., p. 166

${ }^{41}$ Cfr. C. N. Coutinho, Il pensiero politico di Gramsci, cit., p. 28. Una tesis análoga fue apoyada por José Guilherme Merquior.

42 C. N. Coutinho, "La democrazia come valore universale" tr. it. A. Infranca, in Critica Marxista, fasc. 3-4, maggio-agosto 2013, p. 48. 
construcciones ideológicas de la burguesía. No se daban cuenta que el derecho es una conquista de la humanidad entera y no de la burguesía, que tendrá sus formas de derecho, pero esas serán subsumidas, es decir, conservadas y mejoradas por el socialismo. El último Lukács, el ya abiertamente político y democrático, ya consciente que estaba llegando a la vejez, podía permitirse críticas feroces, pero sobre todo estructurales al régimen kadarista, mucho más claro sobre su punto: "Desde esa perspectiva, no hay diferencia entre el derecho socialista y el capitalista, incluso, no se hablaría de derecho socialista, y aquí me remito a Marx. En la Crítica al programa de Gotha, Marx dice muy claramente que el derecho dominante en el socialismo es todavía el derecho civil, sin la propiedad privada, porque el lado formal del derecho fue desarrollado por la civilización capitalista, y esto sin duda permanece en el socialismo en cuanto al derecho. Es indudable que no hay un derecho socialista, sino que el desarrollo del socialismo hacia el comunismo creará un Estado tal en el cual habrá una necesidad de derecho, por lo tanto, no creo que desde este punto de vista se pueda hablar de un derecho socialista especial". ${ }^{43}$ El derecho es uno de los pilares de la democracia moderna sin agregarle el adjetivo burgués, sino de la democracia tout court.

Coutinho no podía conocer ese texto cuando regreso a Brasil desde el exilio, porque fue publicado en 1991 solamente en húngaro y en 2003 en español, pero ese texto entró a ser parte del último libro de Lukács que Coutinho publicó en portugués antes de su muerte. El Lukács que expresa ese juicio drástico, pero significativo, sobre el uso del derecho en la sociedad socialista es el mismo de la Ontología, en cuanto el Testamento político es un texto de 1971, pocos meses antes de que muriese. No hay duda de que la concepción de la democracia fue el hilo de continuidad de Coutinho desde los años ochenta en adelante. De hecho, Coutinho dejo, en primer lugar, el Partido Comunista Brasileño y se acerco al Partido de los Trabajadores (Рт), cansado del extremismo político del РСв у de su exceso de bolchevismo y después participó en la fundación del Partido Socialismo y Libertad (PSOL), cansado de los compromisos políticos del PT, verdaderos verdugos de la democracia. El exilio en Europa le abrió una nueva perspectiva de la democracia, que vio en la obra de emancipación política del Partido Comunista Italiano, el partido fundado por

43 G. Lukács, Testamento político, A. Infranca y M. Vedda eds., Buenos Aires, Herramienta, 2003, p. 173. 
Gramsci, desde los condicionamientos ideológicos del estalinismo y en su secretario político Enrico Berlinguer quien fue el artífice de un continuo crecimiento electoral, que llevo en 1984 al Partido Comunista a ser el primer partido político en Italia, único caso en Occidente de un partido comunista que haya salido de las elecciones como el partido más votado.

La adopción de la democracia como valor universal representa otra operación lógica por parte de Coutinho. Se trata de la adopción de la democracia como un imperativo categórico, no solo como práctica política, sino también como categoría de juicio de la acción del otro. El auténtico demócrata, es decir, aquel que respeta los derechos de los otros en la misma medida que pide sean respetados los suyos, es sin duda un personaje incómodo en la realidad social en desarrollo como la brasileña, pero representa un momento esencial: en Brasil, si bien todavía bajo una dictadura, la realidad social era suficientemente madura para que se pudiesen reivindicar derechos universales. Eran derechos, antes que nada espirituales (como la libertad de expresión, de movimiento, de la sexualidad, de la religión, etc.), y luego individuales (derecho a la alimentación, a la vida, a vestirse, a tener un hogar y una cultura). No se alcanzaron inmediatamente porque la dictadura militar antes, y el establishment burgués después, lo impidieron, pero estaban puestas las bases para reivindicar, sin ninguna vergüenza, por parte de la izquierda brasileña, el derecho a una vida digna de ser vivida. Hasta el momento la satisfacción de aquellos derechos había sido reenviada después de la edificación del socialismo, la reivindicación de Coutinho significó que cada brasileño, independientemente de su condición social, tiene el derecho de denunciar justamente esa condición social. Obviamente, una izquierda ligada a la idea de centralidad del partido, de la obediencia a la Unión Soviética, de la jerarquía de partido, quedó repentinamente desplazada y fuera de lugar. En el mismo grupo de ex jóvenes marxistas una propuesta de esa naturaleza no atrajo las inmediatas simpatías, olía demasiado a eurocomunismo que había sido considerado, bajo las órdenes de Moscú, una enfermedad "senil" del comunismo. Gramsci y también Lukács debían servir para romper con el dogmatismo y esquematismo leninista y estalinista del PCB, por el contrario, acentuaron el aislamiento de Coutinho, tanto que lo indujeron a acercarse al verdadero partido de izquierda de masas que era el PT, pero su jugada puso bajo los ojos de todos la verdadera naturaleza del РСв: un partido sectario, sin ninguna verdadera relación con las masas, una élite subversiva sin futuro. 
Una consecuencia afortunada de ese viraje la tuvo de Gramsci, porque atrajo el interés hacia el pensador político italiano de círculos o ambientes no marxistas, en la confirmación justamente de que la democracia es un valor universal. Era evidente que Coutinho había lentamente quitado la "vía prusiana" lukacsiana y se había quedado con la "revolución desde arriba" ${ }^{44}$ que, sino se convirtió en el crecimiento de la sociedad civil e inicio de una guerra de posición lenta, pero constante, ayudó para conquistar siempre más espacio a las reivindicaciones populares. Este viraje ocurría justamente en el momento en que Brasil tenía un desarrollo industrial y agrario muy poderoso, la impetuosa urbanización desplazaba masas gigantescas de ciudadanos del nordeste hacia las grandes metrópolis de Sao Paulo y de Río de Janerio, la sociedad civil ya se volvía más compleja, en sustancia aquella riqueza antropológica del Brasil se reforzaba y difundía en el país. También la misma izquierda se daba cuenta que si en los años sesentas Cuba era una "Bahía bien lograda", mientras que en los años ochenta Bahía se había vuelto lo que Cuba soñaba ser. No estaban resueltas las grandes contradicciones económicas y sociales, pero la democracia política se arraigó totalmente en el espíritu de los brasileños, tanto que en 1991 el primer presidente de la República, electo con voto popular (Color de Melo) después de la dictadura militar, será destituido por indignidad. Sólo los Estados Unidos habían hecho algo semejante antes en los tiempos del Watergate que precipitaron la caída de Nixon, luego de casi doscientos años de democracia ininterrumpida, Brasil, en cambio sólo tenía dos años de vida democrática. También esa es una señal de lo extraordinario de Brasil.

Gramsci ganaba más lugar en la reflexión política de Coutinho respecto a Lukács, porque con Gramsci emergían mayores instrumentos formales del pensamiento político, ya no más cargados de contenidos ajenos a la historia brasileña, tales como la "vía prusiana" a la modernización. "Revolución desde arriba" o "revolución pasiva" ya habían sido usadas por Coutinho, pero esos conceptos, mejor dicho esas categorías de la política, no tenían en sí un contenido histórico, eran puras formas categóricas utilizables para cualquier formación social. Si se analizan mejor se nota en ellas los rasgos de las categorías aristotélicas: la "revolución desde arriba" indica un movimiento espacial desde arriba hacia abajo, así como la "re-

44 En el prólogo a la reedición de 2000, de una compilación de sus ensayos de los años sesenta, setenta y ochenta, Cultura y Sociedade no Brasil, Coutinho reconoce: "Sin embargo, el uso de la categoría gramsciana se acentúa en los ensayos más recientes, desapareciendo y el replanteando la ortodoxia lukacsiana fácilmente perceptible en los trabajos más viejos" (p. 9). 
volución pasiva" es la respuesta en política de la cotidianidad del "parecer" aristotélico. "Hegemonía" indica una capacidad de atracción y de ser invitados por un grupo social, o modelo cultural, y es también un caso de movimiento espacial, porque es tal la atracción hacia sí.

El único valor ético nuevo que Coutinho propone, es la democracia, o mejor dicho, con Lukács, la "democratización" de la vida política adentro y afuera del Partido Comunista Brasileño, que naturalmente no está en las condiciones de aceptar la propuesta y expulsa a Coutinho y a aquel grupo de jóvenes. La democratización pasa en el ambiente político de la izquierda, sin la superflua afiliación política. Pero la democratización no es una categoría sino un valor ético que se debe practicar con la voluntad y las actitudes éticas y morales adecuadas, no tiene contenidos históricos determinados, no tiene esquemas que se tienen que aplicar a situaciones más o menos análogas, por esa razón la democratización es una liberalización. En la propuesta de Coutinho hay elementos para una comprensión de los movimientos políticos y sociales del Brasil actual, que está viviendo una atormentada relación entre sociedad civil e instituciones políticas: "La superación de la alienación política presupone el fin del 'aislamiento' del Estado, su progresiva reabsorción por parte de la sociedad que lo produjo y desde la cual se alienó; ahora, esto será posible sólo a través de la creciente articulación entre los organismos populares de democracia directa y los mecanismos "tradicionales" de representación indirecta (partidos, parlamentos, etc.). Esta articulación hará que esos últimos adquieran una nueva función -amplíen su grado de representatividad- en la medida en que den lugar a una síntesis política de los varios sujetos políticos colectivos". ${ }^{45}$ Se trata, entonces, de una propuesta de democratización, de una transformación de la política en sentido ético, de una ética pero hecha de valores políticos, de una participación y de una síntesis entre varios sujetos políticos a partir del respeto de la posición del otro. Se nota también la superación de la tradición democrática burguesa en la democracia socialista, que nace en la sociedad civil y es capaz de dar respuestas a las exigencias de ésta. Coutinho habla de "socialización de la política". Una democracia de ese tipo es sin duda una democracia reforzada, porque es capaz de integrar todos los estratos de la sociedad brasileña, extremadamente ligada, como un Todo.

$\overline{45}$ C. N. Coutinho, "La democrazia come valore universale", cit., p. 49. 
Esto también es otro motivo por el que Coutinho confiesa la adopción de Gramsci como pensador universal de la política; la universalidad de Gramsci es la consecuencia de la occidentalización del Tercer Mundo: "Esta universalidad tiene también una dimensión geográfica: se vuelve siempre más evidente que los procesos de occidentalización [...] tienden a extenderse en las áreas situadas fuera del así llamado "Norte" del mundo. Eso hace de la universalidad de Gramsci algo racionalmente concreto para los socialistas del creciente número de países" ${ }^{36}$ La occidentalización es también nombrada, de otra manera, la "modernización" del Tercer Mundo, pero solamente en un proceso terminado (post festum) se pueden reconocer esos rasgos mínimos comunes que permiten la aplicación de las categorías gramscianas a la sociedad civil del Tercer Mundo. También es posible sostener que la universalidad de Gramsci se debe a la formalidad de sus categorías, como explique arriba.

El ejemplo de Carlos Nelson Coutinho sigue siendo válido: la búsqueda filosófica tiene que desbordar desde las universidades y entrar en la carne viva de la sociedad civil. Como para Coutinho, Gramsci y Lukács pueden estar en el centro de la búsqueda de alternativas a un mundo difícil de aceptar, en su pensamiento se descubre no solo en instrumentos de análisis de la sociedad civil contemporánea, sino también propuestas de un desarrollo democrático futuro de la sociedad latinoamericana. Y es verdad que Gramsci y Lukács se están "latinoamericanizando", una demostración de la universalidad de su pensamiento. Han sido capaces de proponer a intelectuales como Coutinho categorías teóricas que eran universales y es normal que cada investigador social, político, teórico, los adopte a su manera, que pongan a prueba la capacidad que tienen esas categorías de adaptarse a la más diversas realidades sociales. En ellos se encuentra, siempre y cada vez una relación directa con el objeto real, porque su materialismo es antes que nada un realismo, en particular, un realismo crítico. Puede que esa universalidad sea también la consecuencia

46 C. N. Coutinho, Il pensiero politico di Gramsci, tr. it. A. Pelliccia, Milano, Unicopli, 2006, p. 162. Indicó el original del portugués para destacar cómo la traducción italiana está muy lejos del original hasta el punto en que haya eliminado un paso esencial del texto: "Esta universidad también tiene una dimensión geográfica: cada vez es más claro que el proceso de occidentalización [...] tienden a generalizar zonas geográficas situadas fuera del ámbito de Europa Occidental a los Estados Unidos, donde Gramsci los había registrado. Esto hace de la universalidad de Gramsci algo nacionalmente concreto para los socialistas de un número creciente de países", en C. N. Coutinho, Gramsci. Um estudio sobre seu pensamento politico, Rio de Janeiro, Civilização Brasileira, 1999, p. 188. 
del hecho que América Latina es una sociedad universal, porque es un Occidente explotable, Otro Occidente, y justamente Gramsci y Lukács, en tanto marxistas auténticos, estuvieron siempre del lado de las víctimas del sistema capitalista, el más eficiente sistema de explotación nunca edificado por el hombre. Estuvieron al lado de las víctimas para ayudarlas a emanciparse y a liberarse de esa explotación; y su ejemplo, de ponerse del lado de las víctimas del sistema fue seguido por aquel grupo de jóvenes intelectuales marxistas, por Coutinho en particular, el cual nunca dudo en creer que un mundo mejor es posible. Carlos Nelson Coutinho se queda como ejemplo de la gran nostalgia de una humanidad integra; a él se puede referir, para concluir, el sentido de su propia frase, sustituyendo el término "artista" por el de "intelectual" o el de "filósofo", y a la palabra "arte" por la palabra "cultura":

Así cuanto más un artista se vincula a la totalidad de las contradicciones de su pueblo y de su nación, cuanto más se vuelve [...] 'hombre de su tiempo y de su país', tanto más le será posible elevarse a aquel nivel de particularidad, de universalidad concreta, sin la cual no existe el gran arte. ${ }^{47}$

\section{BibLIOGRAFÍA}

AGOSTI, HÉCTOR (1993); "Introduzione a Letteratura e vita nazionale", en Gramsci e a America latina, editado por C. N. Coutinho y M. A. Nogueira. São Paulo: Paz y Terra.

AMADO, J. (1996); Bahia de todos os Santos. Guias de ruas e misterios. Rio de Janeiro: Record.

ARICÓ, J. (1991); "Il ruolo degli intellettuali nella diffusione di Gramsci in America latina", tr. A. Infranca, in Gramsci nel mondo, a cura di M. L. Righi, Roma, Istituto Gramsci.

COUTINHO, CARLOS NELSON (1980); A democracia como valor universal, São Paulo, Ciencias Humanas.

, (1993); "As categorias de Gramsci e a realidade brasileira" en Gramsci e a America latina, editado por C. N. Coutinho y M. A. Nogueira. São Paulo: Paz y Terra.

(1999); Gramsci. Um estudio sobre seu pensamento politico. Rio de Janeiro: Civilização Brasileira.

, (2001); "Cultura e società in Brasile", tr. it. A. Infranca, in Rivista di studi portoghesi e brasiliani, a. III, Pisa.

47 C. N. Coutinho, "Cultura e società in Brasile", cit., p. 192. 
, (2006); Il pensiero politico di Gramsci, tr. it. A. Pelliccia, Milano, Unicopli.

, (2011); "Gramsci e noi", en Gramsci in America latina, editado por D. Kanoussi, G. Schirru, G. Vacca, Bologna, Il Mulino.

, (2013); "La democrazia come valore universale" tr. it. A. Infranca, in Critica Marxista, fasc. 3-4, mayo-agosto.

GRAMSCI, A. (1980): “La rinascita gesuitica”, en “¡Avanti!” del 15 enero 1917, publicado en A. G., Cronache torinesi, editado por S. Caprioglio, Torino, Einaudi.

GRAMSCI, A., "Il socialismo e l'Italia”, "Il Grido del popolo”, n 687 del 22 septiembre 1917, en A. G., La città futura, a cura di S. Caprioglio, Torino, Einaudi.

KANT, I. (1979); Critica del giudizio, tr. A. Gargiulo, Bari, Laterza.

LUKÁCS, G. (1959); La distruzione della ragione, tr. it. E. Arnauld, Torino, Einaudi. , Pensiero vissuto, tr. it. A. Scarponi, Roma, Editori Riuniti.

, Testamento político, A. Infranca y M. Vedda eds., Buenos Aires, Herramienta, 2003.

"Presença de Lukács no Brasil. Entrevista com Leandro Konder e Carlos Nelson Coutinho" (2002), en Lukács e a atualidade do marxismo, editado por S. Lessa e M. O. Pinassi, São Paulo, Boitempo.

RIBEIRO, D. (1990); Teoria do Brasil: los brasileros, Petropolis, Vozes.

SECCO, LINCOLN (2002); Gramsci e o Brasil. Recepção e difusão de suas ideais. São Paulo: Cortez.

SIMIONATTO, IVETE (2004); Gramsci. Seu teoria, incidencia no Brasil, influencia no Serviço Social, São Paulo.

Traducción Aldo Guevara y Victor Hugo Pacheco, revisada por José Gandarilla y Lorena Olivares. 